\title{
Spatially Continuous Land-Cover Reconstructions Through the Holocene in Southern Sweden
}

\author{
Robert O’Dwyer, ${ }^{1}$ Laurent Marquer, ${ }^{2,3}$ Anna-Kari Trondman, ${ }^{4}$ and \\ Anna Maria Jönsson ${ }^{1 *}$
}

\begin{abstract}
${ }^{1}$ Department of Physical Geography and Ecosystem Science, Lund University, Lund, Sweden; ${ }^{2}$ Research Group for Terrestrial Palaeoclimates, Max Planck Institute for Chemistry, Mainz, Germany; ${ }^{3}$ Department of Botany, University of Innsbruck, Innsbruck, Austria; ${ }^{4}$ Faculty of Landscape Architecture, Horticulture and Crop Production Science, Swedish University of Agricultural Sciences, Alnarp, Sweden
\end{abstract}

\begin{abstract}
Climate change and human activities influence the development of ecosystems, with human demand of ecosystem services altering both land use and land cover. Fossil pollen records provide time series of vegetation characteristics, and the aim of this study was to create spatially continuous reconstructions of land cover through the Holocene in southern Sweden. The Landscape Reconstruction Algorithm (LRA) was applied to obtain quantitative reconstructions of pollen-based vegetation cover at local scales, accounting for pollen production, dispersal, and deposition mechanisms. Pollen-based local vegetation estimates were produced from 41 fossil pollen records available for the region. A comparison of 17 interpolation methods was made and evaluated by comparing with current land cover. Simple kriging with cokriging using eleva-
\end{abstract}

Received 17 September 2020; accepted 6 December 2020; published online 28 January 2021

Author contributionsROD was responsible for performing the analysis and writing a first version, presented as a master thesis; LM and AMJ supervised the master thesis work, LM and AKT collected, formatted and transformed (by running the LRA) pollen data. AMJ was responsible for revising the text from thesis to manuscript, and all authors have commented and revised the previous versions of the manuscript. All authors have read and approved the final manuscript.

Electronic supplementary material: The online version of this article (https://doi.org/10.1007/s10021-020-00594-5) contains supplementary material, which is available to authorized users. ${ }^{*}$ Corresponding author; $e$ mail: Anna_Maria.Jonsson@nateko.lu.se tion was selected to interpolate the local characteristics of past land cover, to generate more detailed reconstructions of trends and degree of variability in time and space than previous studies based on pollen data representing the regional scale. Since the Mesolithic, two main processes have acted to reshape the land cover of southern Sweden, originally mostly covered by broad-leaved forests. The natural distribution limit of coniferous forest has moved southward during periods with colder climate and retracted northward during warmer periods, and human expansion in the area and agrotechnological developments has led to a gradually more open landscape, reaching maximum openness at the beginning of the 20th century. The recent intensification of agriculture has led to abandonment of less fertile agricultural fields and afforestation with conifer forest.

Key words: Landscape Reconstruction Algorithm; Fossil pollen; Ecosystem services; Land cover; Southern Sweden; Interpolation methods.

\section{HighLIGHTS}

- South Swedish land cover has changed substantially during the past 7500 years. 
- A growing human population and new land use practices induced land cover changes.

- Our land-cover reconstructions provide insight in landscape trends and variability.

\section{INTRODUCTION}

Climate change and human land use have played important roles in the development and sustainability of ecosystems over temporal and spatial scales (for example, Berglund and others 2008). In Europe, climate was the main driver of vegetation changes until about 4500 BP when human activities and population growth started to have a large influence at regional and sub-continental scales (Marquer and others 2017; Kuosmanen and others 2018). Societal development and agricultural inventions led to formation of man-made ecosystems, such as grazed forests, pastures, meadows, and crop fields. The dependence on different ecosystem services has changed over time, in relation to changes in human lifestyle, technological advancements, and development of agricultural practice, with more rapid and extensive changes seen during the past 50 years than in any other time in human history (MEA 2005). Today, the climate is also changing due to human activities; these induced changes in temperature and precipitation may affect ecosystem functioning and distribution of species (IPCC 2014). Knowledge about the past is needed for improved model projections about ongoing climate and land use changes.

A long-term perspective of plant ecosystem changes can be obtained by analysing fossil pollen preserved in sedimentary archives. The European Pollen Database (EPD) (Fyfe and others 2009; Giesecke and others 2014) was developed in the early 1990s to provide a structure to archive, exchange, and analyse quaternary pollen data, covering the continent to represent the major aspects of European vegetation history (for example, Fyfe and others 2015; Giesecke and others 2017; Roberts and others 2018; Zanon and others 2018). In Sweden, fossil pollen studies have provided valuable insights in the development of vegetation over time, in relation for example, to changes in Swedish vegetation composition and diversity over the Holocene, as caused by migration of species, climate change, ecological succession of species, and human activities (Berglund and others 1991, 2008; Björkman 1999; Lindbladh 1999, Lindbladh and others 2008; Cui and others 2014; Hultberg and others 2015; Mazier and others 2015; Fredh and others 2012, 2017, 2019; Hannon and others
2018). Lindbladh and others (2000) were the first to use pollen-based mapping of historical land cover in southern Sweden. Since then, new modelling techniques have been developed, and the number of pollen sites available has increased.

The REVEALS model (Regional Estimates of VEgetation Abundance from Large Sites; Sugita 2007a) has been used to create pollen-based maps of past land cover (Nielsen and others 2012; Trondman and others 2015; Pirzamanbein and others 2014, 2018), accounting for inter-taxonomic differences in pollen production, dispersal and deposition mechanisms at regional scales. Such maps provide generalized pictures of regional landscape development, and information from local pollen estimates would enable mapping local variations within the regional vegetation pattern. The Landscape Reconstruction Algorithm (LRA; Sugita 2007b) has been developed to achieve quantitative pollen-based reconstruction of vegetation cover, accounting for inter-taxonomic differences in pollen production, dispersal and deposition mechanisms at local scales. The LRA works by first using the REVEALS model to estimate the regional vegetation coverage based on pollen records from large lakes ( $>50$ ha). Once the influence of regional vegetation is defined, quantitative reconstruction of local vegetation around smaller sites, lakes, and bogs ( $<50$ ha) can be obtained by using a second model called LOVE. The LRA provides estimates of local land cover (LOVE estimates) in terms of distance weighted abundance of plant taxa within the RSAP (relevant source area of pollen), the smallest spatial unit for which vegetation abundance can be estimated by modelling fossil pollen data (Sugita 2007b). RSAP corresponds to a specific spatial resolution, from a few metres or kilometres around the site where pollen deposited. LRA modelling has been applied in various environmental contexts (for example, Sugita and others 2010; Cui and others 2014; Poska and others 2014; Hjelle and others 2015; Mazier and others 2015; Abraham and others 2017; Marquer and others 2020a). To create spatially continuous land cover maps based on point data, interpolation methods have to be applied. The most commonly used interpolation methods are inverse distance weighting (IDW), kriging and cokriging, with kriging generally having lower prediction bias compared to other methods (Mirzaei and Sakizadeh 2016). The selection of interpolation method is important, as different methods generate different results, and an ensemble of methods can provide additional insights into trends and uncertainties (Araújo and New 2006). 
The aim of this study was to create spatially continuous reconstructions of land cover throughout the Holocene in the southern part of Sweden, to explore the long-term perspective of regional and local vegetation changes. LRA-based vegetation estimates were produced from 41 fossil pollen records available for the region. An ensemble of 17 interpolation methods, which included both deterministic and geostatistical methods (with and without elevation as covariable), was compared to address uncertainties when interpolating over large areas and evaluate the suitability of different methods in comparison with current land cover. One of the best-performing methods was selected for interpolation of 15 past time windows through the Holocene. By applying the interpolated LRA approach to all fossil pollen sites in southern Sweden, this study provides an overview of local variations within a regional context, thus adding an intermediate spatial level to the analysis of pollen data in comparison with earlier studies that focused on specific local conditions (Cui and others 2014; Mazier and others 2015; Fredh and others 2017, 2019) or a large regional scale (Trondman and others 2015; Marquer and others 2014, 2017). The spatial reconstructions depict the increase in human impact on land cover throughout the Holocene. In discussion, the observed trend over time and space was interpreted in terms of human desire for provisioning ecosystem services, such as food and wood, which creates a pressure on the land and lead to altered land use and land cover (Potschin and Haines-Young 2011).

\section{Material ANd Method}

\section{Fossil Pollen Data and Quantitative Vegetation Estimates}

The LRA approach was used to generate local landcover reconstructions based on fossil pollen data for southern Sweden. A detailed description of the algorithms of the REVEALS and LOVE models can be found in the appendices of Sugita (2007a, b). All pollen records were retrieved from the LANDCLIM pollen data archive (Trondman and others 2015, 2016; Marquer and others 2014, 2017) and the EPD network (http://www.europeanpollendatabas e.net/index.php). For the LRA application, we considered twenty-five pollen types and the relative pollen productivity estimates (RPPs) obtained from various regions in Europe (the LANDCLIM standard 2 dataset of Mazier and others (2012)). These RPPs have been previously applied in regional land-cover reconstructions (for example,
Trondman and others 2015; Marquer and others 2014, 2017; Kuosmanen and others 2018) and recent local reconstructions in the South of Finland (for example, Alenius and others 2020). Tables about RPPs and their standard errors, as well as fall speeds of pollen are provided in Marquer and others $(2014,2017)$. The LRA results are expressed as percentage cover of plant species with their standard errors; standard errors were obtained by a delta method (Stuart and Ord 1994).

Pollen counts were grouped into time windows (TW). Initially 44 TWs were selected for the model runs which correspond to the best compromise between a high pollen count, a good temporal resolution, and a continuous time scale. Note that the higher the pollen count the smaller the error estimates of LRA will be. The TW's spanned one 60year period for present time (2010-1950), 50-year periods from 0 to 100 years before present (BP; 0 $\mathrm{BP}=\mathrm{AD} 1950$ ), then 100-year periods from $100 \mathrm{BP}$ back to $3000 \mathrm{BP}$, and 500-year periods from 3000 to $9000 \mathrm{BP}$. This does not apply to Krageholmssjön that has been used for REVEALS runs in Skåne for which the TW's spanned one 110-year period for modern time (2010-1900), 150-year periods (50$200 \mathrm{BP}$ ), then 200 -year intervals from $200 \mathrm{BP}$ back to $3000 \mathrm{BP}$, and 500-year periods from 3000 to $9000 \mathrm{BP}$.

We used the REVEALS v.5.0.exe and LOVE v.5.0.exe computer programs (Sugita, unpublished). Neutral atmospheric conditions and a constant (through space and time) wind speed of $3 \mathrm{~m} \mathrm{~s}^{-1}$ are assumed for the model runs, as it has been done in previous studies (for example, Trondman and others 2015; Marquer and others 2014, 2017, 2020a). The Gaussian plume model (GPM) implemented in REVEALS by Sugita (2007a, b) has been used as modelling scheme to describe dispersal and deposition of pollen grains in the air; see Marquer and others (2020b) for recent discussion about the use of the GPM in LRA reconstructions. Zmax, the maximum spatial extent of the regional vegetation from the centre of the study sites, was set to $100 \mathrm{~km}$. The RSAPs were calculated by using an inverse modelling approach including in the LOVE model. Pollen records were grouped into 3 size intervals ( 0 to $<2$ ha, $2-10$ ha, $>10 \mathrm{ha})$ for the LOVE runs to reduce biases related to basin size on the calculation of the RSAP, that is, a large basin size would lead to a large RSAP and then by using all sites together we would artificially increase or decrease the RSAPs for several sites. The RSAPs (mean of all Holocene TWs) for the pollen sites within the size intervals 0 to $<2$ ha, 2-10 ha, $>10$ ha vary between 250 and 
$790 \mathrm{~m}, 370$ and $1220 \mathrm{~m}$, and 555 and $2715 \mathrm{~m}$, respectively.

The resulting REVEALS estimates and their standard errors consisted of regional plant species abundances for the southernmost and northernmost areas. The REVEALS estimates used as inputs for regional vegetation abundance in LOVE were based on pollen records from the four largest lakes in southern Sweden: Fiolen, Trummen and Kansjön in Småland and Krageholmssjön in Skåne (Table Al). For the LOVE model, pollen records from 41 small study sites located within the borders of the five counties of southern Sweden (Blekinge, Halland, Jönköping, Kronoberg and Skåne) were used (Figure 1). Pollen records from bog and lake were run separately by using different models of pollen dispersal and deposition for bogs (Prentice 1985) and lakes (Sugita 1993). All the sites that have been used in the present study have robust chronological controls and satisfactory time resolutions of Holocene vegetation changes; information about chronologies of pollen sites is given in Trondman and others $(2015,2016)$ and Marquer and others (2017). All the chronologies were based on calibrated years before present (BP through the paper). LOVE estimates were expressed as distance weighted plant abundance within the RSAP for each pollen site.

Fifteen TWs of high quality (high number of pollen sites and low uncertainties in LOVE esti- mates) were selected to cover important steps of land use and societal developments in southern Sweden throughout the Mesolithic period, the Neolithic period, the Bronze Age, the Iron Age, the mediaeval period and the modern period (Table 1). Based on the plant taxa, coverage estimates for five land cover types (LCTs) were calculated with their relative standard errors: Conifer forest, broadleaved forest, shrubs, open land, and arable land (Table 2).

\section{Spatial Interpolation}

Continuous spatial interpolation and mapping were carried out using ArcMap 10, Esri Inc. to compare the outcome of 17 different methods. Four deterministic methods, which create surfaces from the measured points based on the degree of smoothing or extent of similarity, and seven geostatistical methods, which quantify the spatial autocorrelation and account for the spatial configuration of the points around the predicted location, were evaluated in this study. Each method has its own set of parameters that can be customized for different datasets (Table 3). Different kriging methods were included as they differ in terms of assumptions and usability, that is, ordinary kriging assumes that the unknown mean is a constant, simple kriging that the exact mean is known, and universal kriging that the model errors are autocorrelated. Probability kriging estimates the auto-
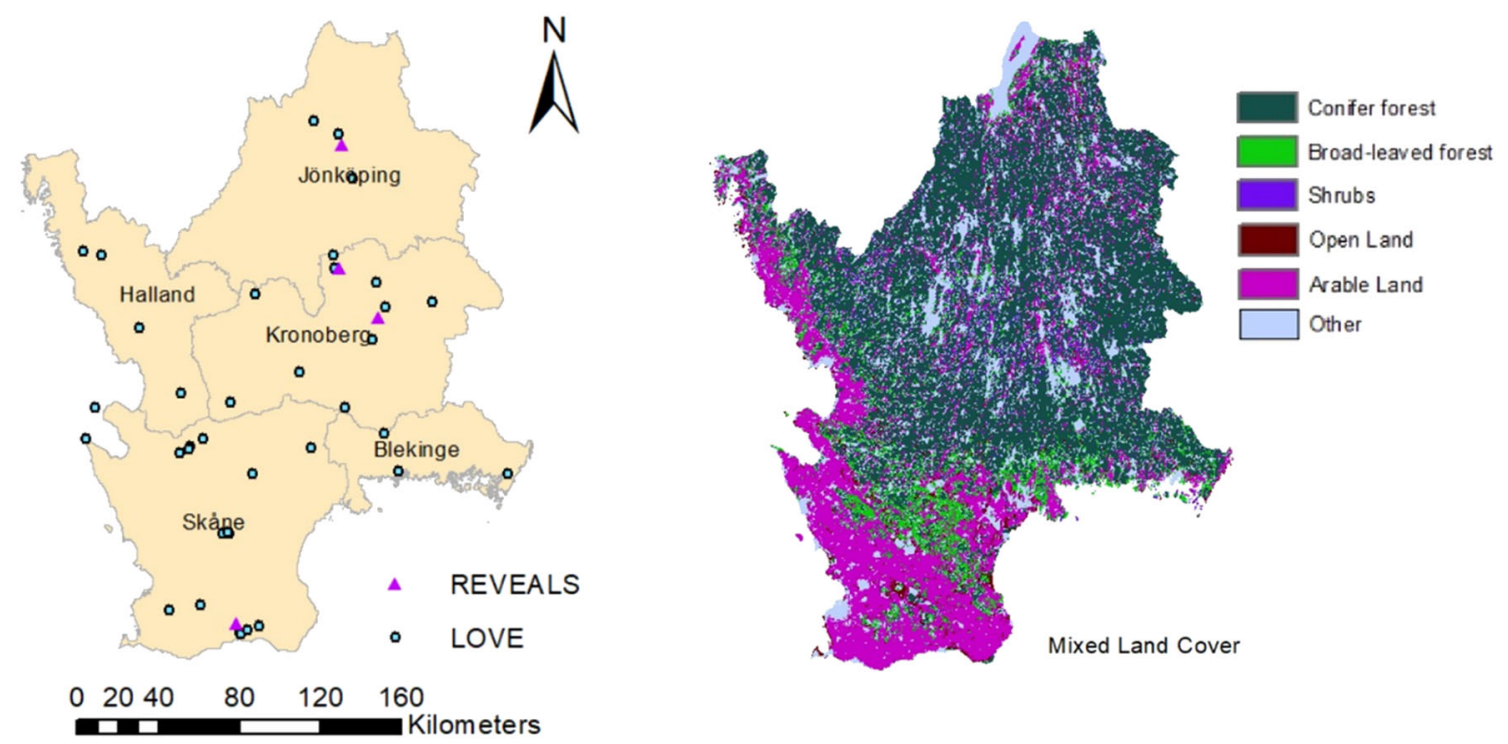

Figure 1. (A) Map of Southern Sweden, showing the 41 sites used for pollen-based LRA modelling (light blue circles) and the four pollen sites for REVEALS runs (purple triangles). The study area included the counties Skåne, Blekinge, Halland and two part of Småland, Jönköping and Kronoberg. Table 2 contains information on the sites from which lake and bog sediment cores had been sampled to provide fossil pollen records. (B) CORINE mixed land cover for the 5 LCTs assessed in this study. 
Table 1. The Time Windows (TWs) Selected for this Study Among the 44 TWs Covering the Last 9000 years, the Number of Pollen Records and Pollen Counts Used in the Analyses, the TW's ppanned Periods in cal y BP as Well as CE/BCE, and the Corresponding Cultural Periods of Swedish History.

\begin{tabular}{lllllll}
\hline TWs & $\begin{array}{l}\text { Number of } \\
\text { records used }\end{array}$ & $\begin{array}{l}\text { Total pollen count } \\
\text { per time window }\end{array}$ & $\begin{array}{l}\text { Mean pollen count per } \\
\text { site (min-max counts) }\end{array}$ & Cal y BP & CE/BCE & Period \\
\hline 1 & 27 & 55,576 & $2060(409-4656)$ & $-60-0$ & $2010-1950$ & Modern \\
2 & 26 & 39,201 & $1510(354-5101)$ & $0-50$ & $1950-1900$ & \\
3 & 29 & 45,000 & $1550(334-7416)$ & $50-100$ & $1900-1850$ & \\
4 & 36 & 95,541 & $2655(356-16,447)$ & $100-200$ & $1850-1750$ & \\
8 & 36 & 69,998 & $1945(327-6032)$ & $500-600$ & $1450-1350$ & Mediaeval \\
10 & 33 & 70,877 & $2150(383-10,082)$ & $700-800$ & $1250-1150$ & \\
13 & 33 & 46,413 & $1410(370-7201)$ & $1000-1100$ & $950-850$ & Viking \\
17 & 32 & 48,946 & $1530(401-11,354)$ & $1400-1500$ & $550-450$ & Migration \\
22 & 28 & 34,913 & $1250(382-5226)$ & $1900-2000$ & $50-50$ & Roman Iron Age \\
25 & 27 & 33,211 & $1230(389-3713)$ & $2200-2300$ & $250-350$ & Pre-Roman \\
& & & & & Iron Age \\
28 & 23 & 31,603 & $1375(414-3626)$ & $2500-2600$ & $550-650$ & Bronze Age \\
33 & 31 & 127,991 & $4130(432-20,341)$ & $3000-3500$ & $1050-1550$ & \\
35 & 29 & 107,555 & $3710(433-22,847)$ & $4000-4500$ & $2050-2550$ & Neolithic \\
37 & 29 & 114,428 & $3945(487-24,714)$ & $5000-5500$ & $3050-3550$ & \\
41 & 20 & 82,252 & $4110(424-22,469)$ & $7000-7500$ & $5050-5550$ & Mesolithic \\
& & & & & \\
\hline
\end{tabular}

Table 2. The 25 Plant Taxa/Pollen Types Used for the Pollen-Based Land-Cover Modelling, Sorted into 5 Land-Cover Types (LCTs).

\begin{tabular}{llll}
\hline Conifer forest & Broad-leaved forest & Shrubs & Open land \\
\hline Abies & Alnus & Juniperus & Artemisia \\
Picea & Betula & Calluna vulgaris \\
Carpinus & Salix & Cerealia-t & Cyperaceae \\
& Corylus & & Filipendula \\
& Fagus & Graminea \\
& Fraxinus & Plantago lanceolata \\
& Quercus & & Plantago media \\
& Tilia & Plantago montana & Rumex acetosa- $t$ \\
& Ulmus & & Secale cereale
\end{tabular}

Note that plant taxa included in Arable land overlap some of those in Open land.

correlation for each variable and their cross-correlation, however, this introduces additional uncertainty. For indicator kriging, every point in the space has an indicator value of either 0 or 1 , and disjunctive kriging assumes bivariate normality.

All geostatistical methods (Table 3) were run both with and without cokriging, except EBK that was too computationally demanding. Cokriging is a variant of the kriging method that takes into account a covariable for interpolation. Elevation has been used as a covariable by Pirzamanbein and others $(2014,2018)$ to create spatially continuous maps of past land cover based on pollen data. In this study, it was selected as a covariable, as the altitudinal variation within the study area (between 0 and $350 \mathrm{~m}$ ) is linked to both bioclimatic and edaphic conditions, including annual mean temperature, precipitation patterns, soil type and texture (SNV 2011). The kriging interpolations were carried out with and without arcsine transformation of the input data, which can be used for data that are in the form of proportions or percentages (which the LOVE data are). 
Table 3. The 17 Interpolation Methods, 4 Deterministic and 7 Geostatistical, Evaluated in this Study.

\begin{tabular}{llll}
\hline & \multicolumn{2}{l}{ Method abbreviation } & Method name \\
\cline { 2 - 3 } & Without cokriging & With cokriging & \\
\hline Deterministic methods & GPI & & Global polynomial interpolation \\
& LPI & & Local polynomial interpolation \\
& IDW & & Inverse distance weighted \\
RBF & & Radial basis functions \\
EBK & DK & DKC & Empirical bayesian kriging \\
& IK & IKC & Disjunctive kriging \\
& OK & OKC & Ordicator kriging \\
& PK & PKC & Probability kriging \\
& SK & SKC & Simple kriging \\
& UK & UKC & Universal kriging
\end{tabular}

These methods have been used to interpolate pollen-based modelling estimates and create land cover maps.

\section{Data Analysis and Evaluation}

The LOVE-based land cover estimates range from 0 to 1 ; 0 means the plant species is absent, and 1 the distance weighted plant abundance within the RSAP is $100 \%$. ArcMap cross-validation for TW 1 (2010-1950) was used to determine how well the interpolation methods predicted values at unknown locations. It worked by a process of removing each point estimate one by one and then making a prediction for those points. That is, the sample points were left out one by one in a leaveone-out test. The land cover of the sample point left out was estimated by interpolation and compared with the LOVE data, representing the actual land cover at the sites. The root mean square error (RMSE) obtained after performing each interpolation indicated how well the model predicted values at unknown locations. A cut-off limit of 0.5 is usually set, RMSE values above this indicate poor models and lower RMSE values a more reliable interpolation; c.f. Pirzamanbein and others 2018. In this study, four out of the 17 models (IK, IKC, PK and PKC), fell above an RMSE of 0.45 .

For further evaluation of interpolation methods, the TW 1 maps were compared with the 2012 CORINE land cover data, a vector database with a $100 \mathrm{~m}$ spatial resolution and a minimum mapping unit of 25 ha, downloaded from the European Environment Agency database (http://www.eea.e uropa.eu/publications/COR0-landcover). Administrative boundary layers of Sweden were downloaded from the DIVA-GIS website (http://www.d iva-gis.org/Data) and used to define the study area in the CORINE land cover dataset. CORINE data have 44 original land cover classes that for our evaluation purposes were converted into the 5 LCTs calculated based on the LOVE estimates (Figure 1). The relation between CORINE land cover and elevation, used in cokriging, was analysed. Visual comparison was carried out to assess the general spatial patterns of all interpolations, followed by a quantitative comparison of one selected method. The temporal differences between CORINE data from 2012 and TW1 that represented an average of land cover over 60 years was taken into account in the discussion of the results. During this time window, major land cover changes occurred in southern Sweden, associated with afforestation driven by urbanization, agricultural intensification with larger farm units, loss of animal husbandry and the conversion of extensive deciduous forests to even-aged, monoculture conifer forests (SNA 2011), whereas the CORINE 2012 land cover data only provide a snapshot in time, not representative of the entire period in a large part of the landscape, the pollen-based estimates provide an integrated measure.

The simple cokriging with elevation and arcsine transformation of data was found to be among the better interpolation methods (see results section) and therefore applied to create maps for all selected TW's and LCT's. For each TW, five maps were created: one map for each of the 5 LCTs. All interpolated LCT surfaces were converted into raster layers with a pixel size of $500 \times 500 \mathrm{~m}$, with the assigned pixel value being based on the cover ranges. Negative values generated by the interpolation were treated as zero. A cover range from 0 to $100 \%$ with steps of $5 \%$ (20 classes) was used for conifer forest, broad-leaved forest and open land, whereas a cover range from 0 to $20 \%$ with steps of 
$1 \%$ (20 classes) was used for shrubs and arable land categories. Different cover ranges were used because shrubs and arable land had lower abundances than conifer forest, broad-leaved forest and open land categories; by using the same cover range for shrubs and arable land as the three other LCTs no variations in shrubs and arable land would have been observed in the maps. Note that a common issue with pollen records is that the further we go back in time, the fewer the number of sites is available. When LCT records were missing for a specific TW at several locations, for example, the arable land for the oldest TWs, no maps were created.

\section{Results}

\section{Cross-Validation Based on TW1}

The cross-validation (Table 4) results revealed that four of the interpolation methods (Table 3), IK, IKC, PK, and PKC, lacked predictive power (RMSE values $\geq 0.45$ ) and these methods were therefore not analysed further. All 13 remaining interpolation methods had RMSE values $<0.33$. The RMSE values did not vary much for conifer forest (RMSE values from 0.23 to 0.27 ), shrubs (0.06 to 0.08 ) and arable land (0.03 to 0.04$)$. Slightly larger variation was found for broad-leaved forest (0.25 to 0.34 ) and open land (0.17 to 0.26). The lowest RMSE values for each of the LCTs are SKC and DKC for conifer forest (0.23), OK and UK for broad-leaved forest (0.25), SKC, DKC, SK, and DK for shrubs (0.06), UK, SK, OK, and DK for open land (0.17), and SKC for arable land (0.03). SKC was considered as the best method, with top performance (lowest RMSE) for three of five LCTs.

\section{Comparison with CORINE Land Cover Data}

The visual comparison of TW 1 maps produced by different interpolation methods with current land cover (only considering methods with RMSE $<0.45$ ) was carried out to compare the spatial trends of the regional land cover. The deterministic methods indicated the general trends, with GPI and LPI giving a rough regional indication of high and low values for the different land coverages. The geostatistical methods, EBK, OKC and UKC, produced similar patterns (Figure 2). IDW and RBF, among the best methods for broad-leaved forest (Table 4), produced circular areas, strongly influenced by local coverage and gradients between the different sampling sites (Figure 2).

The geostatistical methods, DK, OK, SK and UK, produced mixed combinations of curved lines and circular patterns (Figure 3). More realistic surfaces were produced by DKC and SKC (cokriging with elevation), and for conifer forest and arable land, the pattern resembled these CORINE land cover classes. SKC with arcsine transformed data had

Table 4. RMSE Values of the 17 Interpolation Methods (Table 3) Assessed in This Study.

\begin{tabular}{lllllll}
\hline Interpolation methods & Conifer forest & Broad-leaved forest & Shrubs & Open Land & Arable Land \\
\hline Deterministic & GPI & 0.25 & 0.34 & 0.08 & 0.26 & 0.04 \\
& LPI & 0.25 & 0.3 & 0.07 & 0.22 & 0.04 \\
& IDW & 0.27 & 0.27 & 0.07 & 0.18 & 0.04 \\
Geostatistical & RBF & 0.26 & 0.27 & 0.07 & 0.18 & 0.04 \\
& EBK & 0.25 & 0.28 & 0.07 & 0.19 & 0.04 \\
& DK & 0.24 & 0.28 & $\mathbf{0 . 0 6}$ & $\mathbf{0 . 1 7}$ & 0.04 \\
IK & 0.5 & 0.52 & 0.5 & 0.46 & 0.45 \\
OK & 0.25 & $\mathbf{0 . 2 5}$ & 0.07 & $\mathbf{0 . 1 7}$ & 0.04 \\
& IK & 0.5 & 0.52 & 0.51 & 0.46 & 0.45 \\
SK & 0.24 & 0.28 & $\mathbf{0 . 0 6}$ & $\mathbf{0 . 1 7}$ & 0.04 \\
UK & 0.25 & $\mathbf{0 . 2 5}$ & 0.07 & $\mathbf{0 . 1 7}$ & 0.04 \\
DKC & $\mathbf{0 . 2 3}$ & 0.31 & $\mathbf{0 . 0 6}$ & 0.23 & 0.04 \\
IKC & 0.5 & 0.52 & 0.51 & 0.46 & 0.45 \\
OKC & 0.25 & 0.33 & 0.07 & 0.23 & 0.04 \\
PKC & 0.52 & 0.52 & 0.51 & 0.52 & 0.48 \\
SKC & $\mathbf{0 . 2 3}$ & 0.31 & $\mathbf{0 . 0 6}$ & 0.23 & 0.03
\end{tabular}

For each land cover type, bold numbers indicate the methods providing the lowest RMSE (top performances). Methods for which the RMSE exceeded 0.45 (marked with italics) were not analysed further. 


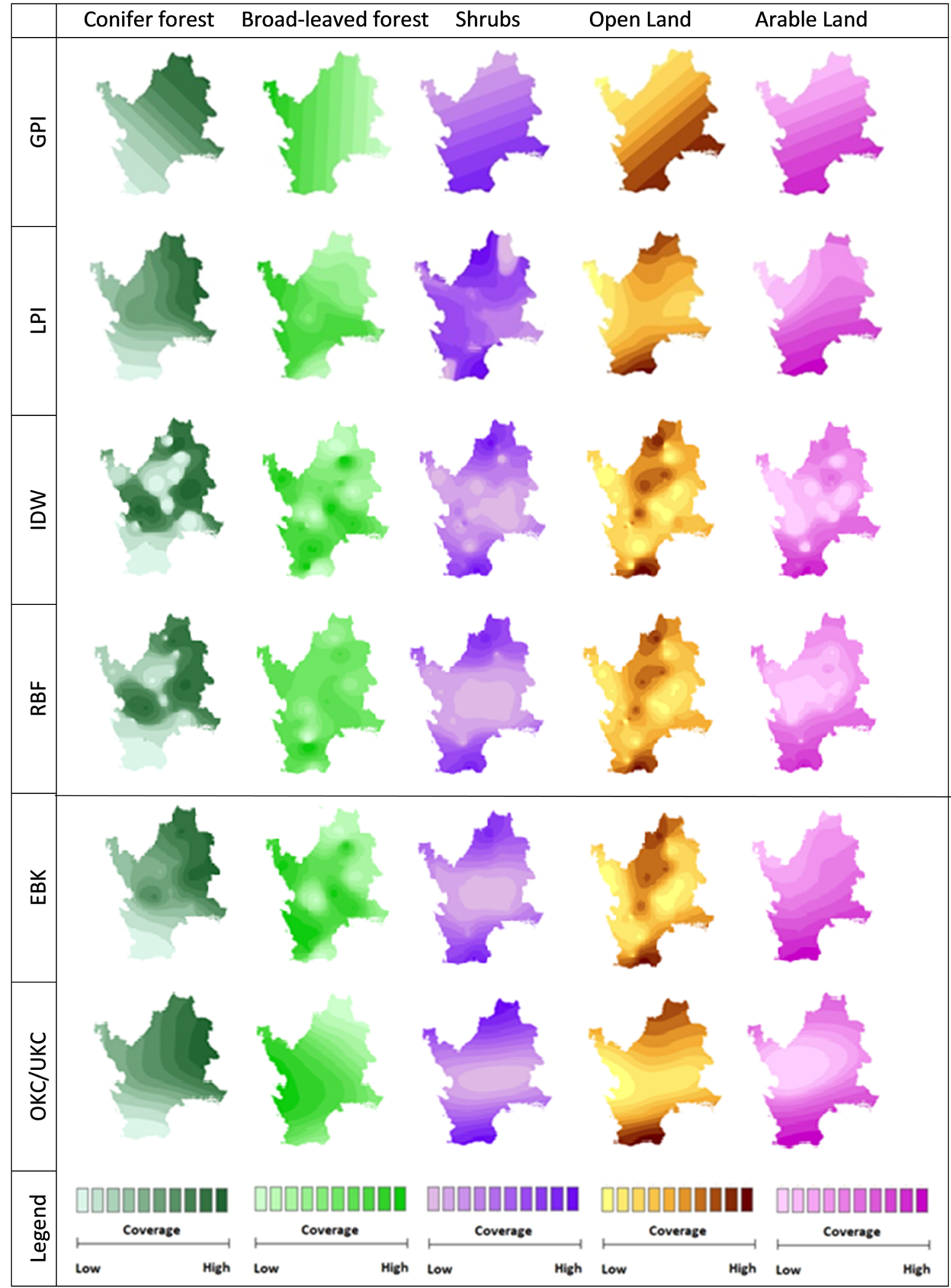

Figure 2. Maps of conifer forest, broad-leaved forest, shrubs, open land and arable land for TW 1 (2010-1950), interpolated using deterministic methods, and two geostatistical methods (EBK, OKC/UKC) producing geometric patterns (Table 3). For detailed legends with scaled bars see appendix (Table A2). For RMSE values see Table 4. 
similar, slightly improved RMSE values compared with SKC without transformation, but produced more realistic surfaces for arable land, capturing the fields of the west coast (Figure 3). This interpolation method (denoted SKC arcsine) was therefore also used for the past TWs.

The resulting interpolated maps represent smoothings of complex, mosaic landscapes, in which the land cover class values are linked to the likely occurrence of different land class combinations. Elevation was used for cokriging, and a comparison between elevation and the CORINE land cover classes showed that higher elevation areas $(>100 \mathrm{~m})$ are currently dominated by conifer forest, and low land areas $(<50 \mathrm{~m})$ are predominantly agricultural areas (Figure 4A). The intermediate zone includes a mixture of broadleaved forest, conifer forest, and agricultural land. A comparison between the SKC arcsine interpolated land cover classes and the CORINE land cover classification showed in general good agreement (Figure 4B). Areas indicated by the SKC arcsine interpolation as having a low cover of conifer forest were predominantly $(>85 \%)$ classified in CORINE as having another land cover, and areas indicated as having a high cover of conifer forest were predominately classified as conifer forest $(>80 \%)$. The arable land provided a similar picture, interpolated areas having a low cover of arable land were associated with conifer forest, and areas with a high cover of arable land were predominantly classified in CORINE as arable land. For broadleaved forest, the interpolated cover was substantially higher than shown by the CORINE land cover, whereas for arable land and conifer forest the interpolated covers were lower than observed. The comparison between two data sets indicated the recent time changes, with broad-leaved forest becoming less common in the landscape due to the intensification of agriculture in the south-western part and conversion to conifer forest in the northeastern part of the study area. Also, shrubs and open land indicated the recent time changes, with plantation of conifer forest on former pasture land.

\section{Spatial Changes in Land Cover Types Through Time}

The interpolated LOVE estimates depicted the land cover transitions of southern Sweden (Figure 5). The landscape was dominated by broad-leaved forest during the Mesolithic. From 7250 to 75 BP, the coverage of broad-leaved forest was reduced from above $80 \%$ to $55-25 \%$, with substantial local variations, followed by a slight general increase from $25 \mathrm{BP}$ to present time. Currently, nemoral broad-leaved forests are mainly located in the southern part of the study area. Our results showed a temporary decrease during the Bronze Age that might have been caused by the increase in population density and land use at that time. During the modern time period conifer forest became dominant in a large part of the study area. The opening of the land observed from about $2500 \mathrm{BP}$, accelerated during the Bronze Age and continued until the modern period. Between 0 and $30 \%$ of the landscape was open between 7250 and 3250 BP, 35 to $70 \%$ of the landscape was open $75 \mathrm{BP}$, and present time values are $15-25 \%$. Through time, shrubs covered a relatively small fraction of the land. Shrubs decreased in abundance from $5 \%$ in 7250 BP to $0-1 \%$ in 2250 BP. Peak abundance was indicated for $75 \mathrm{BP}$, with up to $17 \%$ coverage in the north-eastern part, followed by a decrease to $1-$ $5 \%$ in present time. The arable land, covering a minor fraction since the Neolithic, expanded in the modern period. Less than $1 \%$ of the landscape was arable land in $4250 \mathrm{BP}$ and has since then increased to up to $4 \%$ at present in the southernmost part.

The two REVEALS reconstructions (Figure 6) for the southernmost (Skåne) and northernmost (Småland) areas of the study region, supported the general temporal trends of land cover change that was observed in the interpolated LRA estimates, that is, Skåne was subjected to an earlier and more pronounced opening of the landscape than Småland. The REVEALS data also confirm regional differences in forest landscape properties, with Småland having a generally higher proportion of conifer forest than Skåne. Arable land (Figure 7) is recorded earlier (ca. $4500 \mathrm{BP}$ ) in Småland than Skåne (ca. 4000 BP), and the extent of arable land is generally larger in Skåne (maximum cover over the Holocene of $34 \%$ at ca. $200-400 \mathrm{BP}$ ) than in Småland (maximum $4.7 \%$ at ca. $400-500 \mathrm{BP}$ ).

\section{Discussion}

In this study, we explored the spatial and temporal patterns of land cover changes in southern Sweden. Pollen records, transformed by LRA modelling to distance weighted plant abundance throughout Holocene, provided local point estimates of land cover (LOVE data) at 41 locations. A key focus was to evaluate different methods for interpolation of the point estimates to create continuous spatial maps for selected time windows that represent the major cultural periods in southern Sweden. Considering all regions in Europe, southern Sweden 


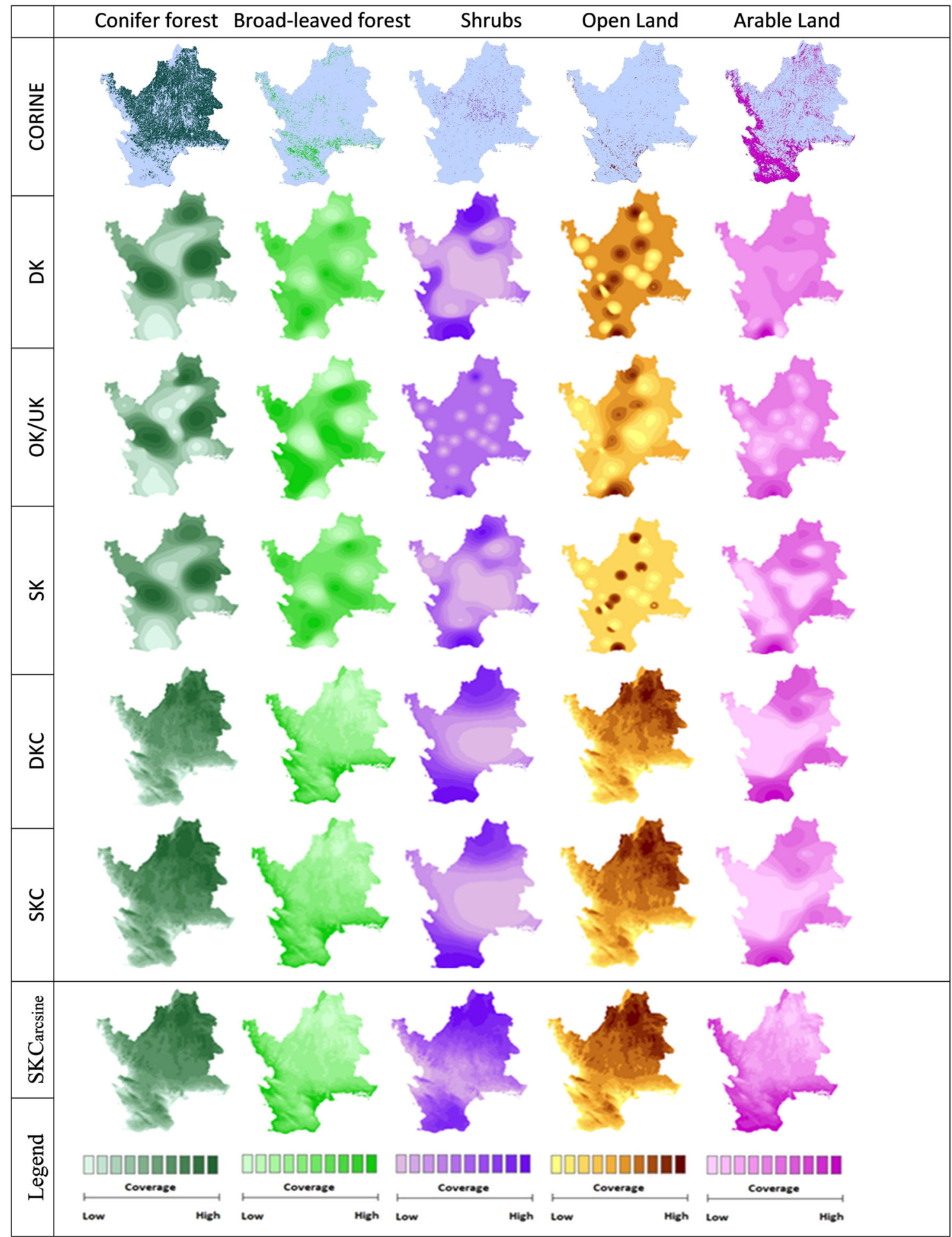

Figure 3. Maps of conifer forest, broad-leaved forest, shrubs, open land and arable land for TW 1 (2010-1950) interpolated using geostatistical methods (Table 3). The top left row represents land cover classes as depicted by the CORINE land cover data for visual evaluation of the interpolation methods. For detailed legends with scaled bars see appendix (Table A2). For RMSE values see Table 4. 

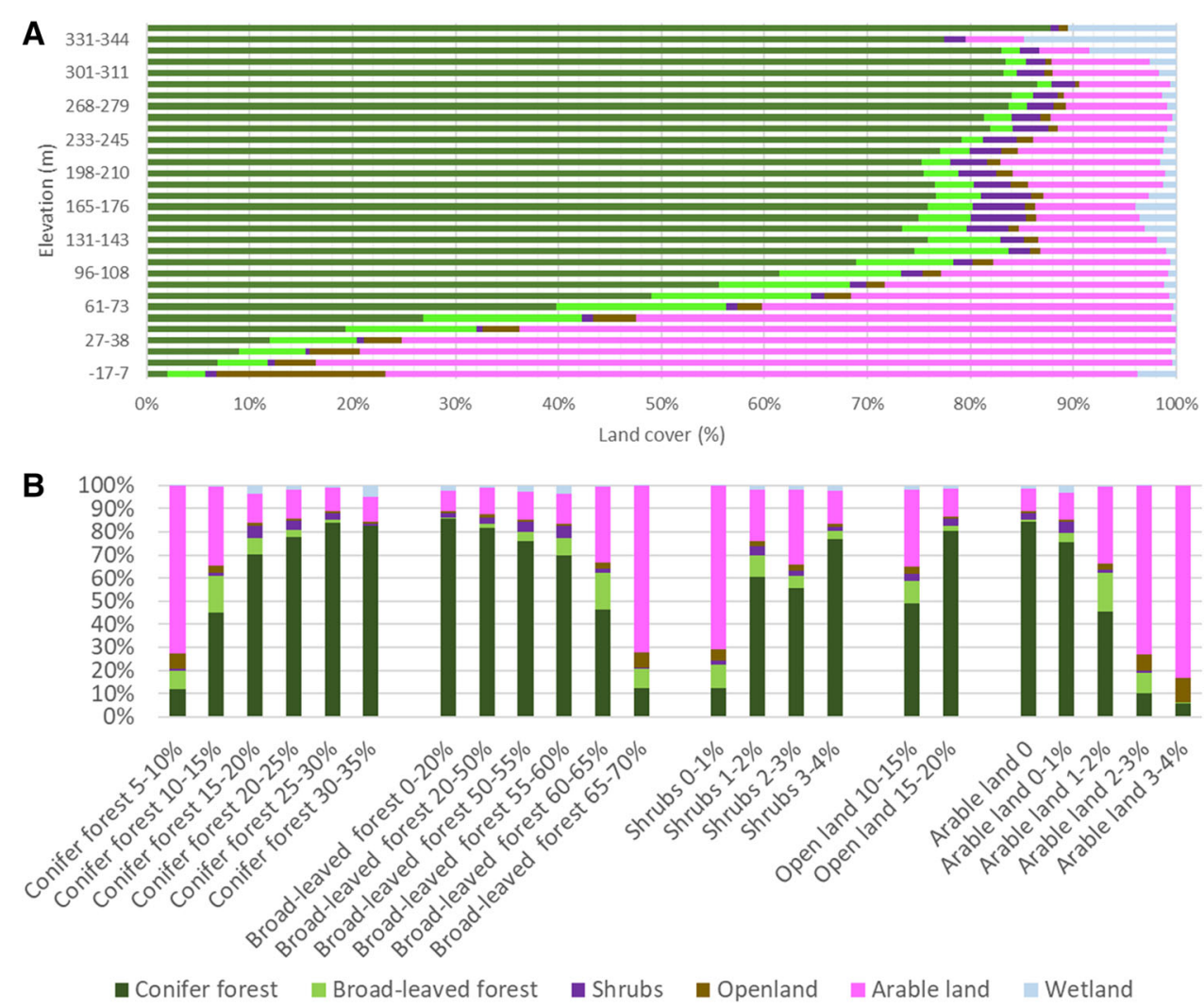

Figure 4. (A) Comparison between elevation and CORINE land cover. (B) Comparison between the land cover classes (LCT) obtained by SKC arcsine interpolation based on LOVE estimates and the CORINE 2012 land cover classification. The bars represent the proportions of each LCT based on CORINE (y-axis) for classes of LCTs based on SKC arcsine interpolation (x-axis). For details see appendix and Table A2. The correspondence between the LCT and CORINE land cover classes is as follows: Conifer forest = coniferous forest; broad-leaved forest = broad-leaved forest; shrubs = moors and heathland + transitional woodland-shrub; open land = natural grasslands + pastures + sparsely vegetated areas; arable land $=$ non-irrigated arable land + fruit trees and berry plantations + land principally occupied by agriculture + complex cultivation patterns; wetland $=$ peat bogs + inland marshes + salt marshes .

has one of the highest concentrations of pollen records (c.f. Fyfe and others 2009), and it is thus a suitable region to attempt land cover mapping based on LOVE data to explore the local variability.

\section{Evaluation and Uncertainties of the Spatial Land-Cover Reconstructions}

Thirteen of the 17 interpolation methods were able to provide a picture of the current land cover in southern Sweden, thereby allowing for the capturing of variability within the region at a more detailed level than previous regional land-cover reconstructions (c.f. Trondman and others 2015; Marquer and others 2017; Pirzamanbein and others 2018). The resulting maps were influenced by the number, distribution and value ranges of the LOVE data points, in combination with the methodspecific characteristics. The relevant source area of pollen (RSAP, see Sugita 2007b for definition) represents the known vegetation coverage of each data point, corresponding to 41 point estimates of a radius of 250 to $2715 \mathrm{~m}$ (mean over the Holocene; RSAP estimates are influenced by the basin size and landscape mosaic. The landscape reconstructions based on local point data were associated with rather high RMSE values in the leave-one-out test, around 0.25 for conifer and broad-leaved forest cover. This is related to the patchiness of a landscape managed by multiple land owners. This means that just next to a grassland there might be a forest, whereas the interpolated maps show gradual spatial changes. The resulting land cover values should be interpreted in relation to the interpolation method used. In general, the interpolation methods with a high degree of smoothing had a smaller range of values than the methods capturing local variability (Table A2), which is in line with the commonly observed differences between point- 


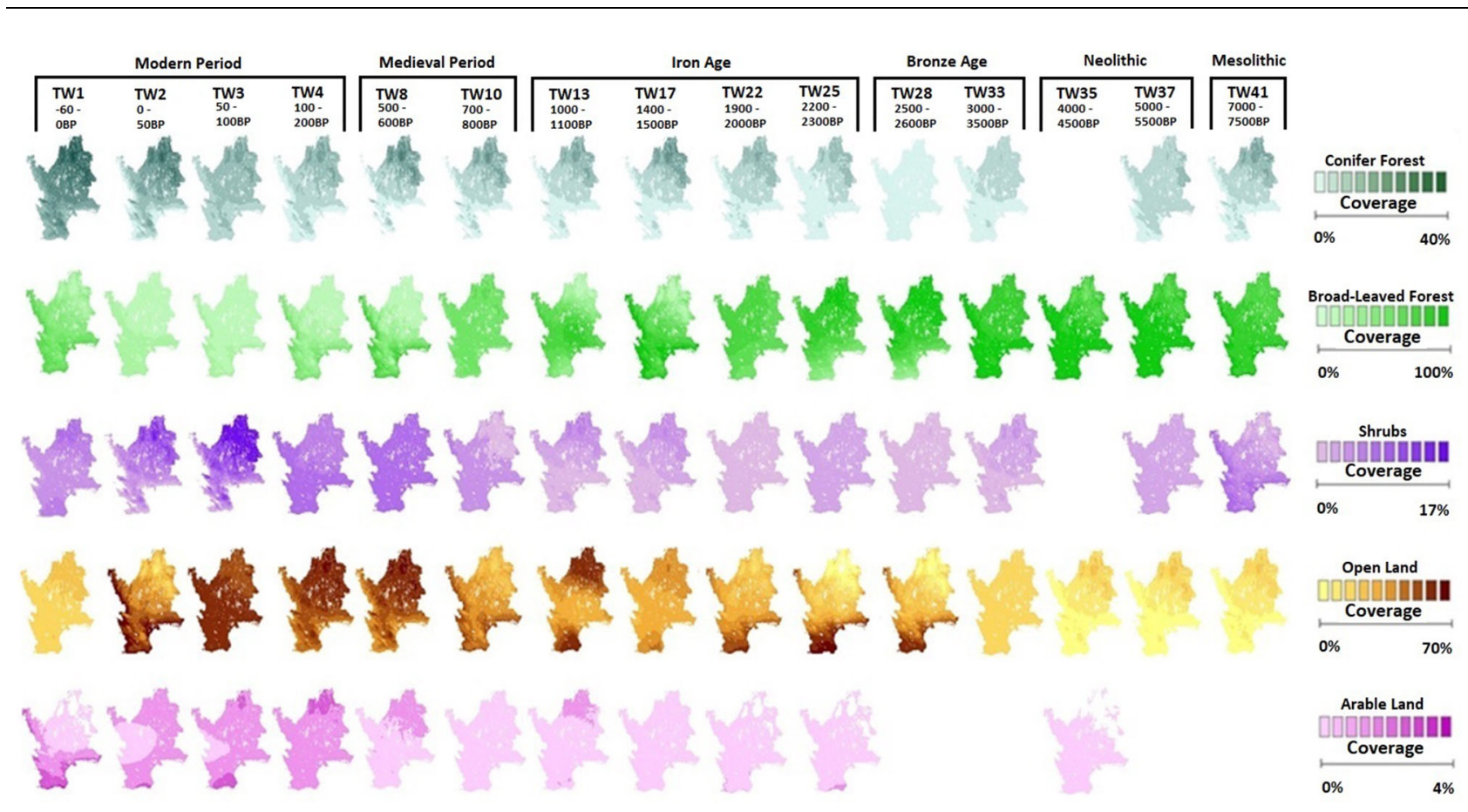

Figure 5. Pollen-based maps of broad-leaved forest, conifer forest, shrubs, open land and arable land produced by simple kriging with cokriging (SKC; altitude as covariable) and arcsine transformation of LOVE estimates. The maps are shown for the selected time windows (see Table 1) and the major cultural periods of southern Sweden.

level data and grid-level (averaged) data in distribution properties and ability to capture extremes (Director and Bornn 2015). The interpolated data were transformed to a raster with $500 \times 500 \mathrm{~m}$ pixels, enabling the mapping of trends, but as seen from the TWl-maps, the density of data points was not sufficient to provide any details at such a high resolution.

In analogy to ensemble modelling of species distributions (Araújo and New 2006), the use of several interpolation methods can be used and analysed together to obtain information on trends, robust patterns and uncertainties. Our study showed that the different interpolation methods emphasized different aspects of the general landscape coverage, with similar magnitudes of RMSE (Table 4). The geometric patterns produced by the deterministic methods provided an overview of spatial trends, with the GPI maps being sensitive to outliers, and the LPI maps to the chosen neighbourhood distance. The IDW maps depicted both general trends and local patchiness of a landscape managed by humans, as defined by the search neighbourhood. Two geostatistical methods, DKC and SKC, produced more realistic interpretations of the local landscape patterns. That is, cokriging with elevation was found to better capture variability than simple or disjunctive kriging based on LOVE data only. Despite relatively low differences in altitude (between 0 and $350 \mathrm{~m}$ ) in southern Sweden, there is a strong relation between elevation and current land cover (Figure 4A). The last glacial period had a major impact on the landscape, with the topography influencing the distribution of different moraine soil types (SNV 2011). Therefore, also the links between elevation and land use through time are strong. Early settlements occurred around the coast and in low land areas, and elevation-dependent edaphic and climatic factors have had a major impact on which parts of the landscape that were explored for settlements and agriculture (Klein Goldewijk and others 2011; Wei and others 2020).

A full ensemble analysis of past time windows was beyond the scope of this study, and the method selected for interpolation of past TWs was SKC arcsine. This method was one of the top performing in terms of RMSE values, and the arcsine transformation of pollen data had the advantage of generating normal distributions with relatively low variance. A quantitative comparison between the CORINE 2012 land cover data and TWl ("present time", from 1950 to 2010) showed high agreement in areas dominated by conifer forest and agriculture, respectively. Low correspondence was found for the other land cover categories, that is, areas indicated in TW 1 as covered by broad-leaved forest, shrubs and open land were all dominated by con- 

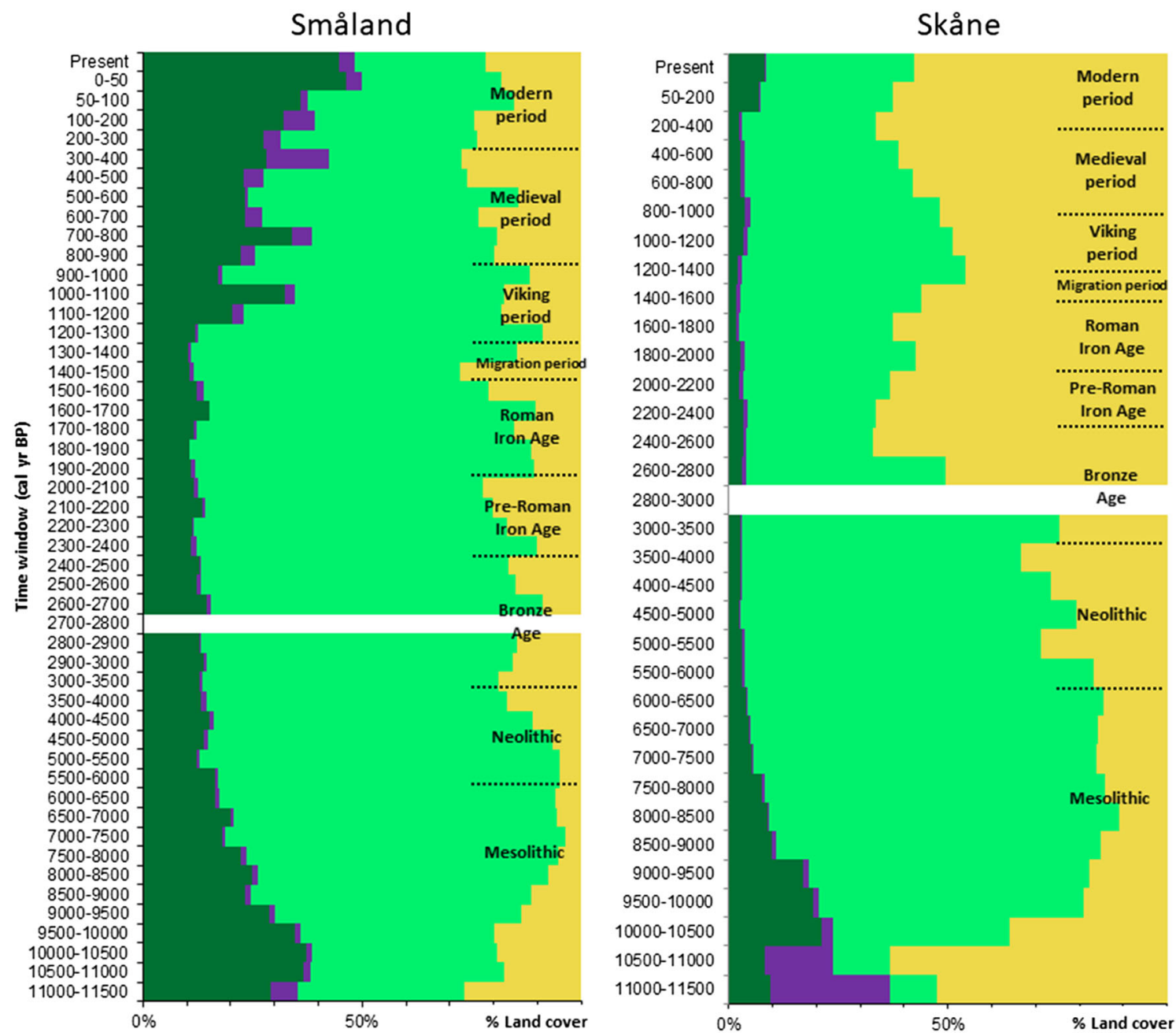

Figure 6. REVEALS estimates for a combination of three large sites (lakes) in Småland and for one large lake in Skåne (Figure 1A), indicating the trend in percentage vegetation cover during the past 11,500 years, including changes in conifer forests (dark green), shrubs (purple), broad-leaved forest (light green) and open land (brown). Arable land (Figure 7) is included in the category open land.

ifer forest and agriculture. That is, this comparison between a snapshot in time (CORINE 2012) and a 60 -year time window, was indicative of the substantial land use and land cover changes that has occurred towards modernisation and intensification of forestry and agriculture in southern Sweden (Blennow and Hammarlund 1993; Lindbladh and others 2014; SNV 2011). An additional explanation for low correspondence is that the LOVE estimates of broad-leaved forest were dominated by birch, whereas birch naturally grows in both conifer and broad-leaved forests. That is, birch was considered in both broad-leaved and conifer categories of the CORINE dataset, whereas it was only included in the LCT broad-leaved forest based on LOVE estimates. It should also be noted that the arable land category based on LOVE estimates was based on two common pollen types only, Cerealia and Secale, which created an underestimation of arable land. That is, a scale of $0-4 \%$ was used for mapping the arable land, however, an average of about $8 \%$ of the land area in Sweden is currently arable (SNV 2011). Additional information on pollen grains from other crops and ruderal plants would have contributed to a more complete picture.

\section{Spatial and Temporal Changes in Holocene Land Cover in Southern Sweden}

In the following part, we used the spatially continuous reconstructions of land cover throughout the Holocene to explore vegetation changes. Since the Mesolithic, two main processes have acted to reshape the land cover of southern Sweden, origi- 

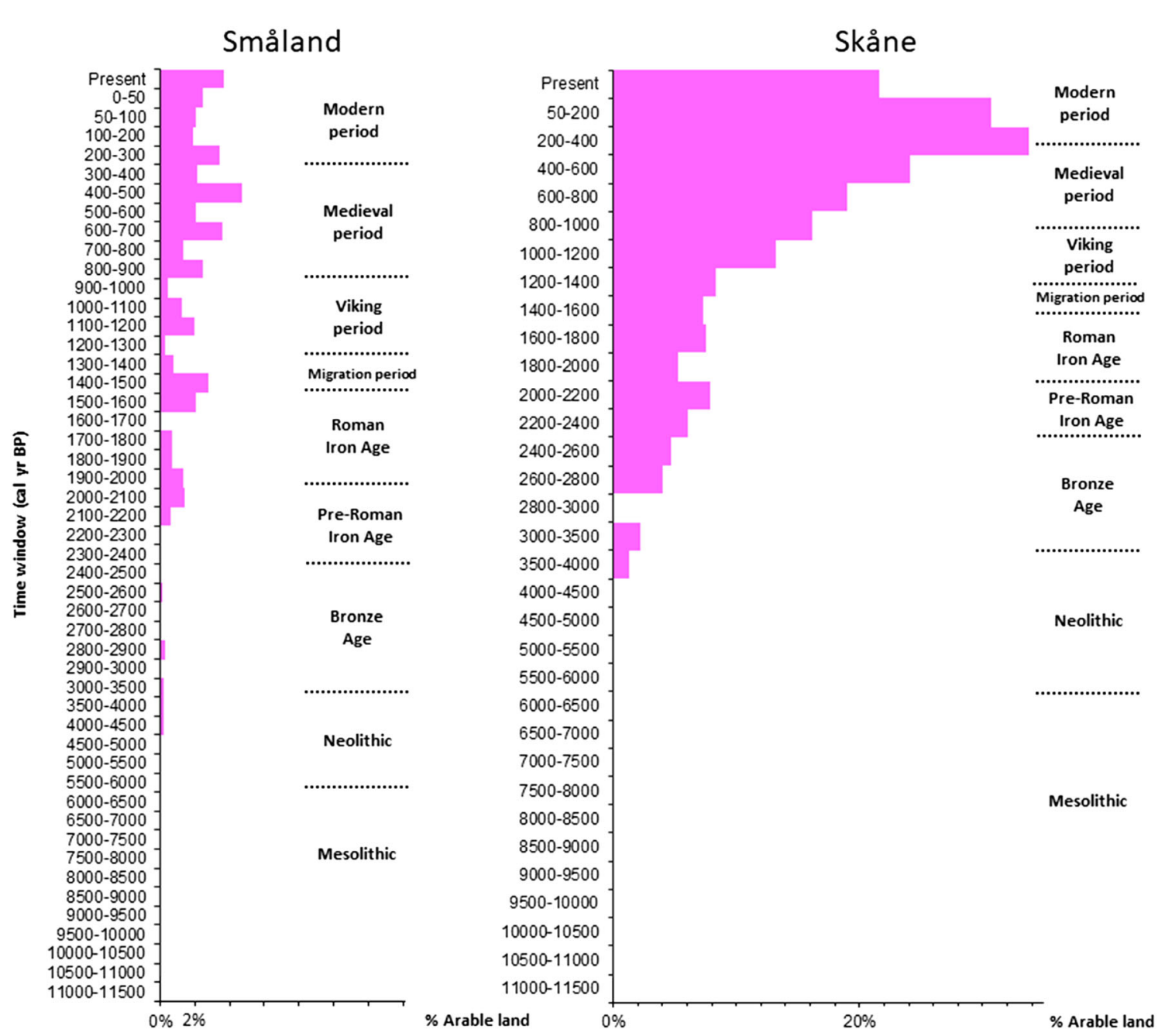

Figure 7. REVEALS estimates for a combination of three large sites (lakes) in Småland and for one large lake in Skåne (Figure 1A), indicating the trend in percentage cover of arable land during the past 11,500 years.

nally covered by broad-leaved forests. Since the last glaciation, the natural distribution of Norway spruce forest has expanded from the north-eastern part of Scandinavia and moved southward (Giesecke and Bennett 2004), and the arable land was developed stepwise by technological interventions and the periodic growth and decline of human population (Berglund 2003; Eriksson and Cousins 2014). Lowest forest cover and maximum open land were reached at the beginning of the 20th century (Li and others 2013; Wei and others 2020).

The Mesolithic landscape was mainly covered by natural vegetation, in south Sweden dominated by nemoral broad-leaved forest, in the north-eastern part in a mix with about $20 \%$ boreal coniferous forest. The high forest cover is in line with the low human impact around the Baltic catchment at that time (Fyfe and others 2015; Kuosmanen and others 2018; Marquer and others 2014, 2017). Also, the
Neolithic landscape was dominated by broadleaved forest, covering $85-100 \%$ in all of southern Sweden. The pollen-based LCT maps indicate that $5-15 \%$ of the land was open, and that conifer forest was on retreat in the north-eastern part, likely due to climate related disturbances (storms, insect outbreaks, and/or forest fires) rather than human impact. Little to no arable land was indicated for the northeast part, and below $1 \%$ of the rest of southern Sweden was arable. The climate cooling from about 6000 BP (Imbrie and others 1992) was contemporaneous with the start of human-induced opening of the landscape.

The Bronze Age maps indicated up to $55 \%$ forest cover in the south-eastern part and above $70 \%$ in other parts of southern Sweden. This pattern is in agreement with earlier studies, which found that forest cover around 3000 BP was dominated by mixed deciduous forest (Björkman and Bradshaw 
1996), and that forest cover was below $40 \%$ in the southernmost part of Sweden (Eriksson and Cousins 2014). In the Bronze Age, southern Skåne and coastal areas of Halland and Blekinge were converted into open land (Berglund 1988, 2003), first to improve grazing for livestock and over time to create arable land for cultivation of crops (Lindbladh 1999; Hannon and others 2018), with manure being used as a fertiliser from around $2500 \mathrm{BP}$ (Eriksson and Cousins 2014).

The pre-Roman Iron Age (earliest part of the Iron Age in Scandinavia) brought with it a new practice of stabling livestock for overwintering (Eriksson and Cousins 2014). The growing need of grasslands for hay-making is seen in the maps of the Iron Age as an expansion of open land, up to $70 \%$ in the south. The inland was still covered by nemoral broad-leaved forest. During the Roman Iron Age, only limited areas in the south were covered by forest, in line with the management practice of burning to keep the landscape open for pasture and grazing (Blennow and Hammarlund 1993; Cui and others 2014). After the collapse of the Roman Empire and the start of the Migration period, open land was abandoned (reduced to about $40 \%$ ) and overgrown by broad-leaved forest in the south, and conifer forest expanded to $10-25 \%$ in central and northern parts of southern Sweden.

The maps of the Viking period indicated increased arable land cover. Open land increased from about $35 \%$ to more than $50 \%$ in most parts, and also the northern area opened up at the expense of forest cover. The period is associated with an intensification of agriculture, with infields being used for cereal cultivation and outfields for forest grazing and slash-and-burn agriculture (Lindbladh 1999; Fredh and others 2017). The Mediaeval maps did not indicate the decline of pastures and meadows that have been reported in association with the Black Death pandemic that struck Sweden during 500-600 BP and the colder climate conditions (Little Ice Age) leading to the mid-Mediaeval agrarian crisis (Björkman and Bradshaw 1996; Berglund 2003; Fredh and others 2017). However, the maps showed increased broad-leaved forest in the south and along the coasts, and a general expansion of shrub cover from $2-3 \%$ to $3-4 \%$ by the mid to late Mediaeval Period, and an expansion of conifer forest to 10$30 \%$ of central and northern southern Sweden, likely linked to the reduction of open land. The trend was reversed in the first part of modern period.
The second part of the modern period was associated with a peak in both open land (up to 65\%) and an abundance of shrub cover (in general 4$5 \%$, up to $17 \%$ in the north-eastern part) and the lowest cover of broad-leaved forest (around 25\%). The onset of the agricultural revolution was linked to a general increase in arable land, with broadleaved forests being cleared and lakes and wetlands drained (Eriksson and Cousins 2014). Presently, arable land $(3-4 \%)$ is once more found in confined areas such as Skåne and along the coastal regions (Fredh and others 2017). Forest covers $70 \%$ of the land and is dominated by planted conifer forest $(>40 \%)$ in all of southern Sweden (Cui and others 2014; Lindbladh 1999).

\section{ConClusion}

In this study, we explored the potential to use LOVE-based interpolations of local land cover to provide insights in spatial trends and degree of variability within a larger landscape. The use of multiple interpolation methods were found to provide complementary aspects, with deterministic methods indicating general, large-scale trends, and geostatistical methods capturing local variations. A complete ensemble analysis, comparing the results of different interpolation methods covering different time windows was not feasible to carry out. For the study region, cokriging with elevation was found useful, due to a strong correlation between elevation and edaphic factors, having an influence on land use suitability through Holocene. The method selected for mapping of the 15 time windows, simple kriging with cokriging using arcsine transformed data enabled the generation of a more detailed picture of the previously known trends in land cover and land use change of the study region. Mapping land cover from regional to local scales provides insights into landscape patterns. This is a new opportunity for the research communities related to palaeoecology, archaeology, and history as well as landscape management and ecology. In particular, such approaches can be used for landscape spatial pattern analysis for studying landscape changes over a long-term perspective, to get a better understanding of the status, trends, and possible future changes of land cover and ecosystem in general.

\section{ACKNOWLEDGEMENTS}

This study was carried out as part of a master thesis project in Geographical Information Science at the 
Department of Physical Geography and Ecosystem Science, Lund University.

\section{FUNDING}

Open Access funding provided by Lund University.

\section{DATA AVAILABILITY}

Detailed information on the data used in this study and references to sources can be found in the appendix. Table Al. Metadata of the 45 fossil pollen records (41 for LOVE \& 4 for REVEALS), spread over South Sweden by location (site name), with site label, coordinates, elevation, area of site, radius of site, and basin type. For the details about the sources of the pollen data, see Trondman and others $(2015,2016)$ and Marquer and others (2017).

\section{OPEN ACCESS}

This article is licensed under a Creative Commons Attribution 4.0 International License, which permits use, sharing, adaptation, distribution and reproduction in any medium or format, as long as you give appropriate credit to the original author(s) and the source, provide a link to the Creative Commons licence, and indicate if changes were made. The images or other third party material in this article are included in the article's Creative Commons licence, unless indicated otherwise in a credit line to the material. If material is not included in the article's Creative Commons licence and your intended use is not permitted by statutory regulation or exceeds the permitted use, you will need to obtain permission directly from the copyright holder. To view a copy of this licence, visit $h$ ttp://creativecommons.org/licenses/by/4.0/.

\section{REFERENCES}

Abraham V, Novak J, Houfkova P, Petr L, Dudova L. 2017. A Landscape Reconstruction Algorithm and pedoanthracological data reveal Late Holocene woodland history in the lowlands of the NE Czech Republic. Review of Palaeobotany and Palynology 244:54-64.

Alenius T, Marquer L, Molinari C, Heikkilä M, Ojala A. 2020. The environment they lived in. Anthropogenic changes in local and regional vegetation composition in eastern Fennoscandia during the Neolithic. Vegetation History and Archaeobotany. https://doi.org/10.1007/s00334-020-00796W.

Araújo MB, New M. 2006. Ensemble forecasting of species. Trends in Ecology and Evolution 22:42-7.

Berglund, B.E. 1988. The cultural landscape-past, present and future. Cambridge University Press 241-254.
Berglund BE, Malmer N, Persson T. 1991. Landscape-ecological aspects of long-term changes in the Ystad area. Ecological Bulletins 41:405-24.

Berglund BE. 2003. Human impact and climate changes-synchronous events and a causal link? Quaternary International 105:7-12.

Berglund BE, Gaillar M-J, Björkman L, Persson T. 2008. Longterm changes in floristic diversity in southern Sweden: Palynological richness, vegetation dynamics and land-use. Vegetation History and Archaeobotany 17:573-83.

Björkman L, Bradshaw R. 1996. The immigrations of Fagus sylvatica L. and Picea abies (L.) Karst. into a natural forest stand in southern Sweden during the last 2000 years. Journal of Biogeography 23:235-44.

Björkman L. 1999. The establishment of Fagus sylvatica at the stand-scale in southern Sweden. The Holocene 9:237-45.

Blennow K, Hammarlund K. 1993. From Heath to Forest: LandUse Transformation in Halland, Sweden. Ambio 22:561-7.

Cui Q-Y, Gaillard M-J, Lemdahl G, Stenberg L, Sugita S, Zernova G. 2014. Historical land-use and landscape change in southern Sweden and implications for present and future biodiversity. Ecology and Evolution 4:3555-70.

Director H, Bornn L. 2015. Connecting point-level and gridded moments in the analysis of climate data. Journal of Climate 28(9):3496-510.

Eriksson O, Cousins SAO. 2014. Historical landscape perspectives on grasslands in Sweden and the Baltic region. Land 3:300-21.

Fredh D, Broström A, Zillen L, Mazier F, Rundgren M, Lagerås P. 2012. Floristic diversity in the transition from traditional to modern land-use in southern Sweden A.D. 1800-2008. Vegetation History and Archaebotany 21:439-52.

Fredh D, Mazier F, Bragée P, Lagerås $\mathrm{P}$, Rundgren M, Hammarlund D, Broström A. 2017. The effect of local land-use changes on floristic diversity during the past 1000 years in southern Sweden. The Holocene 27:694-711.

Fredh D, Lagerås P, Mazier F, Björkman L, Lindbladh M, Broström A. 2019. Farm establishment, abandonment and agricultural practices during the last 1,300 years: a case study from southern Sweden based on pollen records and the LOVE model. Vegetation history and archaeobotany 28:529-44.

Fyfe RM, de Beaullue JJ, Binney H, Bradshaw RHW, Brewer S, Le Flao A, Finsinger W, Gillard M-J, Giesecke T, Gil-Romera G, Grimm EC, Huntley B, Kunes P, Kühl N, Leydet M, Lotter AF, Tarasov PE, Tonkov S. 2009. The European Pollen Database: past efforts and current activities. Vegetation History and Archaebotany 18:417-24.

Fyfe RM, Woodbridge J, Roberts N. 2015. From forest to farmland: pollen-inferred land cover change across Europe using the pseudobiomization approach. Global Change Biology 21:1197-212.

Giesecke T, Bennett KD. 2004. The Holocene spread of Picea abies (L.) Karst. in Fennoscandia and adjacent areas. Journal of Biogeography 31:1523-48.

Giesecke T, Davis B, Brewer S, Finsinger W, Wolters S, Blaauw M, de Beaulieu J-L, Binney H, Fyfe RM, Gaillard M-J, GilRomera G, van der Knaap WO, Kuneš P, Kühl N, van Leeuwen JFN, Leydet M, Lotter AF, Ortu E, Semmler M, Bradshaw RHW. 2014. Towards mapping the late Quaternary vegetation change of Europe. Veget Hist Archaeobot 23:75-86.

Giesecke T, Brewer S, Finsinger W, Leydet M, Bradshaw RHW. 2017. Patterns and dynamics of European vegetation change 
over the last 15,000 years. Journal of Biogeography 44:144156.

Hannon G, Halsall K, Molinari C, Boyle J, Bradshaw HW. 2018. The reconstruction of past forest dynamics over the last 13,500 years in SW Sweden. The Holocene 28:1791-800.

Hjelle KL, Mehl IK, Sugita S, Andersen GL. 2015. From pollen percentage to vegetation cover: evaluation of the Landscape Reconstruction Algorithm in western Norway. Journal of Quaternary Science 30:312-24.

Hultberg T, Gaillard M-J, Grundmann B, Lindbladh M. 2015. Reconstruction of past landscape openness using the Landscape Reconstruction Algorithm (LRA) applied on three local pollen sites in a southern Swedish biodiversity hotspot. Vegetation History and Archaebotany 24:253-66.

Imbrie J, Boyle EA, Clemens SC, Duffy A, Howard WR, Kukla G, Kutzbach J, Martinson DG, McIntyre A, Mix AC, Molfino B, Morley JJ, Peterson LC, Pisias NG, Prell WL, Raymo ME, Shackleton NJ, Toggweiler JR. 1992. On the structure and origin of major glaciation cycles 1 . Linear responses to Milankovitch forcing. Paleoceangraphy 7:701-38.

IPCC, 2014: Climate Change 2014: Synthesis Report. Contribution of Working Groups I, II and III to the Fifth Assessment Report of the Intergovernmental Panel on Climate Change [Core Writing Team, R.K. Pachauri and L.A. Meyer (eds.)]. IPCC, Geneva, Switzerland, 151 pp.

Klein Goldewijk K, Beusen A, Van Drecht G, De Vos M. 2011. The HYDE 3.1 spatially explicit database of human-induced global land-use change over the past 12,000 years. Global Ecology and Biogeography 20:73-86.

Kuosmanen N, Marquer L, Tallavaara M, Molinari C, Zhang Y, Alenius T, Edinborough K, Pesonen P, Reitalu T, Renssen H, Trondman A-K, Seppä H. 2018. The role of climate, forest fires and human polulation size in Holocene vegetation dynamics in Fennoscandia. Journal of Vegetation Science 29:382-92.

Li B, Jansson U, Ye Y, Widgren M. 2013. The spatial and temporal change of cropland in the Scandinavian Peninsula during 1875-1999. Regional Environmental Change 13:1325-36.

Lindbladh M. 1999. The influences of former land-use on vegetation and biodiversity in the boreo-nemoral zone of Sweden. Ecography 22:485-98.

Lindbladh M, Bradshaw R, Holmqvist BH. 2000. Pattern and process in south Swedish forests during the last 3000 years, sensed at stand and regional scales. Journal of Ecology 88:113-28.

Lindbladh M, Niklasson M, Karlsson M, Björkman L, Churski M. 2008. Close anthropogenic control of Fagus sylvatica establishment and expansion in a Swedish protected landscapeimplications for forest history and conservation. Journal of Biogeography 35:682-97.

Lindbladh M, Axelsson AL, Hultberg T, Brunet J, Felton A. 2014. From broadleaves to spruce - the borealization of southern Sweden. Scandinavian Journal of Forest Research 29:686-96.

Marquer L, Gaillard M-J, Sugita S, Trondman A-K, Mazier F, Nielsen AB, Fyfe RM, Odgaard BV, Alenius T, Birks HJB, Bjune AE, Christiansen J, Dodson J, Edwards KJ, Giesecke T, Herzschuh U, Kangur M, Lorenz S, Poska A, Schult M, Seppä H. 2014. Holocene changes in vegetation composition in northern Europe: why quantitative pollen-based vegetation reconstructions matter. Quaternary Science Reviews 90:99216.

Marquer L, Gaillard MJ, Sugita S, Poska A, Trondman AK, Mazier F, Nielsen AB, Fyfe RM, Jönsson AM, Smith B, Kaplan JO, Odgaard BV, Alenius T, Birks HJB, Bjune AE, Christiansen
J, Dodson J, Edwards KJ, Giesecke T, Herzschuh U, Kangur M, Koff T, Latałowa M, Lechterbeck J, Lorenz S, Olofsson J, Schult M, Seppä H. 2017. Quantifying the effects of land-use and climate on Holocene plant composition and vegetation change in Europe. Quaternary Science Reviews 171:20-37.

Marquer L, Mazier F, Sugita S, Galop D, Houet T, Faure E, Gaillard MJ, Haunold S, de Munnik N, Simonneau A, De Vleeschouwer F, Le Roux G. 2020a. Pollen-based reconstruction of Holocene land-cover in mountain regions: evaluation of the Landscape Reconstruction Algorithm in the Vicdessos valley, Northern Pyrenees, France. Quaternary Science Reviews 228:106049.

Marquer L, Mazier F, Sugita S, Galop D, Houet T, Faure E, Gaillard MJ, Haunold S, de Munnik N, Simonneau A, De Vleeschouwer F, Le Roux G. 2020b. Reply to Theuerkauf and Couwenberg comment on: "Pollen-based reconstruction of Holocene land-cover in mountain regions: Evaluation of the Landscape Reconstruction Algorithm in the Vicdessos valley, northern Pyrenees, France". Quaternary Science Reviews . h ttps://doi.org/10.1016/j.quascirev.2020.106463.

Mazier F, Gaillard MJ, Kunes P, Sugita S, Trondman AK, Broström A. 2012. Testing the effect of site selection and parameter setting on REVEALS-model estimates of plant abundance using the Czech Quaternary Palynological Database. Rev. Palaeobot. Palynology 187:38-49.

Mazier F, Broström A, Bragee P, Fredh D, Stenberg L, Thiere G, Sugita S, Hammarlund D. 2015. Two hundred years of landuse change in the south Swedish uplands: comparison of historical map-based estimates with a pollen-based reconstruction using the landscape reconstruction algorithm. Vegetation History and Archaeobotany 24:555-70.

MEA, 2005. MA conceptual framework in Millennium Ecosystem Assessment (pp. 25-36). Island Press.

Mirzaei R, Sakizadeh M. 2016. Comparison of interpolation methods for the estimation of groundwater contamination in Andimeshk-Shush Plain, South West of Iran. Environmental Science and Pollution Research 23:2758-69.

Nielsen AB, Giesecke T, Theuerkauf M, Feeser I, Behre K-E, Beug H-J, Chen S-H, Christiansen J, Dörfler W, Endtmann E, Jahns S, de Klerk P, Latalowa M, Vad Odgaard B, Rasmussen P, Stockholm JR, Voigt R, Wiethold J, Wolters S. 2012. Quantitative reconstructions of changes in regional openness in north-central Europe reveal new insights into old questions. Quanternary Science Reviews 47:131-49.

Poska A, Saarse L, Koppel K, Nielsen AB, Avel E, Vassiljev J, Vali V. 2014. The Verijarv area, South Estonia over the last millennium: A high resolution quantitative land-cover reconstruction based on pollen and historical data. Review of paleobotany and palynology 207:5-17.

Pirzamanbein B, Lindström J, Poska A, Sugita S, Trondman A-K, Fyfe R, Mazier F, Nielsen AB, Kaplan JO, Bjune AE, Birks HJB, Giesecke T, Kangur M, Latalowa M, Marquer L, Smith B, Gaillard M-J. 2014. Creating spatially continuous maps of past land cover from point estimates: A new statistical approach applied to pollen data. Ecological Complexity 20:127-41.

Pirzamanbein B, Lindström J, Poska A, Gaillard M-J. 2018. Modelling Spatial Compositional Data: Reconstructions of past land cover and uncertainties. Spatial statistics 24:14-31.

Potschin MB, Haines-Young RH. 2011. Ecosystem services: Exploring a geographical perspective. Progress in Physical Geography 35:575-94.

Roberts N, Fyfe RM, Woodbridge J, Gaillard M-J, Davis BAS, Kaplan JO, Marquer L, Mazier F, Nielsen AB, Sugita S, 
Trondman A-K, Leydet M 2018. Europe's lost forests: a pollenbased synthesis for the last 11,000 years. Scientific Reports $8(1)$.

SNA 2011. National atlas of Sweden: a cartographic description Agriculture and forestry in Sweden since 1900/special editor: Ulf Jansson, theme manager: The Royal Swedish Academy of Agriculture and Forestry. Norstedt 2011. ISBN: 9789187760617; 9187760045.

Sugita S. 2007a. Theory of quantitative reconstruction of vegetation I. Pollen from large lakes reveals regional vegetation. The Holocene 17:229-41.

Sugita S. 2007b. Theory of quantitative reconstruction of vegetation II: All you need is LOVE. The Holocene 17:243-57.

Sugita S, Parshall T, Calcote R, Walker K. 2010. Testing the Landscape Reconstruction Algorithm for spatially explicit reconstruction of vegetation in northern Michigan and Wisconsin. Quaternary research 74:289-300.

Trondman A-K, Gaillard M-J, Mazier F, Sugita S, Fyfe R, Nielsen $\mathrm{AB}$, Twiddle C, Barratt P, Birks HJB, Bjune AE, Björkman L, Broström A, Caseldine C, David R, Dodson J, Dörfler W, Fischer E, Van Feel B, Giesecke T, Hultberg T, Kalnina L, Kangur M, Van Der Knaap P, Koof T, Kunes P, Lagerås P, Latalowa M, Lechterbeck J, Leroyer C, Leydet M, Lindbladh M, Marquer L, Mitchell FJG, Odgaard BV, Peglar SM, Persson T, Poska A,
Rösch M, Seppä H, Veski S, Wick L. 2015. Pollen-based quantitative reconstructions of Holocene regional vegetation cover (plant-functional types and land-cover types) in Europe suitable for climate modelling. Global Change Biology 21:67697.

Stuart A, Ord K. 1994. Kendall's Advanced Theory of Statistics, Volume 1: Distribution Theory, 6th Edition, Holder Arnold, London. pp. 912.

Trondman A-K, Gaillard M-J, Sugita S, Björkman L, Greisman A, Hultberg T, Lagerås $\mathrm{P}$, Lindbladh $\mathrm{M}$, Mazier F. 2016. Are pollen records from small sites appropriate for REVEALS model-based quantitative reconstructions of past regional vegetation? An empirical test in southern Sweden. Vegetation History and Archaebotany 25:131-51.

Wei X, Widgren M, Li B, Ye Y, Fang X, Zhang C, Chen T. 2020. Dataset of cropland cover from 1690 to 2015 in Scandinavia. Earth System Science Data . https://doi.org/10.5194/essd-20 20-187.

Zanon M, Davis BAS, Marquer L, Brewer S, Kaplan JO. 2018. European Forest Cover During the Past 12,000 Years: A Palynological Reconstruction Based on Modern Analogs and Remote Sensing. Frontiers in Plant Science 9:253. https://doi. org/10.3389/fpls.2018.00253. 